\title{
Position and Density of Pistillate Inflorescences of Some Hazelnut Cultivars Grown in Iran
}

\author{
Abdollah Hosseinpour ${ }^{1}$, Esmaeil Seifi ${ }^{1} \&$ Thomas J. Molnar ${ }^{2}$ \\ ${ }^{1}$ Department of Horticulture, Faculty of Plant Production, Gorgan University of Agricultural Sciences and Natural \\ Resources, Gorgan, Iran \\ ${ }^{2}$ Department of Plant Biology and Pathology, Rutgers University, 59 Dudley Road, New Brunswick, New Jersey \\ 08816, USA \\ Correspondence: Abdollah Hosseinpour, Department of Horticulture, Faculty of Plant Production, Gorgan \\ University of Agricultural Sciences and Natural Resources, Gorgan, Golestan Province, Iran. Tel: \\ 98-935-726-9790. E-mail: hosseinpour88@gmail.com
}

Received: February 17, 2013 Accepted: March 29, 2013 Online Published: May 15, 2013

doi:10.5539/jas.v5n6p125 URL: http://dx.doi.org/10.5539/jas.v5n6p125

\begin{abstract}
Little work has been done to examine the position and density of pistillate inflorescences (PIs) in hazelnut. In this study, characteristics of PIs of three Iranian cultivars ("Pashmine", "Tabestane", and "Shastak") and three imported cultivars ("Barcelona", "Merveille", and "Prostorika") were examined over one year and compared. Overall, results showed strong similarities between cultivars in density of flowering shoots per branch with the density of PIs notably higher in the upper section of the branches. Significant variation was observed between cultivars in the percent of terminally and laterally located PIs and average number of pistillate flowers per inflorescence. However, more PIs per inflorescence did not necessarily result in more nuts per cluster or higher yield. These preliminary results indicate that the Iranian and imported cultivars share many similar PI characteristics. However, they also suggest that other genetic and environmental factors contribute to nuts produced per cluster and total crop yield. The results provide a foundation from which further studies can be completed on the relationships between PIs and yield in hazelnut.
\end{abstract}

Keywords: Corylus avellana L., filbert, floral density, inflorescence, pistillate flowers

\section{Introduction}

Flowers, the reproductive parts of most plants, are essential to the fruiting process. Therefore, in tree crops including hazelnut (Corylus avellana L.), they are of great economic importance. Efficient commercial production largely depends on the quantity and quality of flower buds produced (Hanke, Flachowsky, Peil, \& Hättasch, 2007). According to Werner, Mowrey and Chaparro (1988), the initial number of flowers differentiated in the previous season is the first component of yield in fruit trees and has a significant impact on productivity. This component of yield has been found to be genotype dependent with large variations in bud density observed in peach (Prunus persica L.) (Okie \& Werner, 1996).

In almond, flower density, fruit set, fruit density, and productivity, are highly affected by the cultivar, year, and environment (Kodad \& Socias i Company, 2006; Socias i Company, Alonso, \& Aparisi, 2004). Similarly, Alburquerque, Burgos and Egea (2004) suggested that in apricot (Prunus armeniaca L.), flower bud density, bud drop, and yield efficiency are also influenced by cultivar. They demonstrated that early flowering cultivars typically had the highest flower bud density. Thus, estimation of flower density and subsequent fruit set is important in assessment of a cultivar's performance (Socias i Company, Felipe, Aparisi, García, \& Dicenta, 1998). Seifi, Guerin, Kaiser and Sedgley (2011) reported that in olive (Olea europaea L.) cultivars, the section of shoot (upper, middle, and basal) affected the inflorescence length and the number of flowers per inflorescence, but not the percent of perfect flowers present. They also found that shoot orientation (north, south, east, and west) did not have any influence on these characteristics in all studied cultivars. This type of information can be helpful for breeders when selecting cultivars as parents in breeding programs to produce progeny with higher cropping efficiency. 
Hazelnut is an obligate out-crossing, monoecious, wind-pollinated shrub with a sporophytic self-incompatibility system (Mehlenbacher, 1997). During flowering season, which occurs in the late winter through early spring depending on the cultivar, it is possible to simultaneously observe staminate (catkins) and pistillate inflorescences (PIs) on the leaf scar axils of one-year-old shoots. This species has a unique reproduction process where pollen lands on the stigma, germinates, and grows down the style, but then remains dormant for approximately five months before fertilizing the egg cell (Thompson, Lagerstedt, \& Mehlenbacher, 1996; Germain, 1994). Pistillate inflorescences are located singly on shoots, on catkin peduncles, or adjacent to vegetative buds (Figures 1 to 4 ). (Germaine, 1994). The relative amounts of PIs in these positions varies between the cultivars (Thompson et al., 1996). It has been shown that the highest-yielding cultivars, such as Ennis, Casina, Montebello, and Willamette, generally have most of their PIs born on catkin peduncles (Thompson et al., 1996). The number of PIs produced is affected by three major factors, which includes available light, origin of PIs on the stem, and the overall vigor of growth of the one-year-old shoots (Germain, 1994). Since the number of flowers is strongly related to yield in hazelnut, an important objective in breeding programs is selecting cultivars with heavy annual flowering capacity (Thompson et al., 1996).

Notwithstanding its importance, there has been little emphasis on describing the position and density of hazelnut PIs in the literature. The objective of this preliminary study was to investigate and document these traits in local hazelnut cultivars in comparison to imported cultivars grown in Iran. This data would then be compared to nuts per cluster and total yield to draw conclusions on the relationship between PI characteristics, fruit set, and crop potential in Iran.

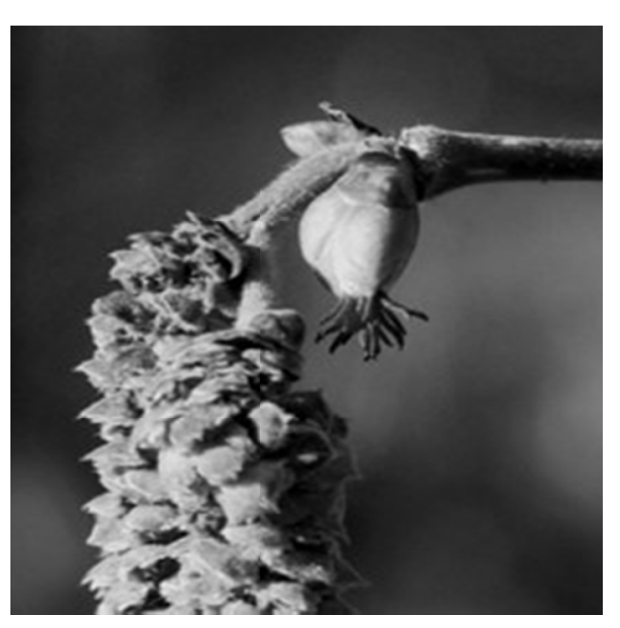

Figure 1. Pistillate inflorescence (PI) on catkin peduncle

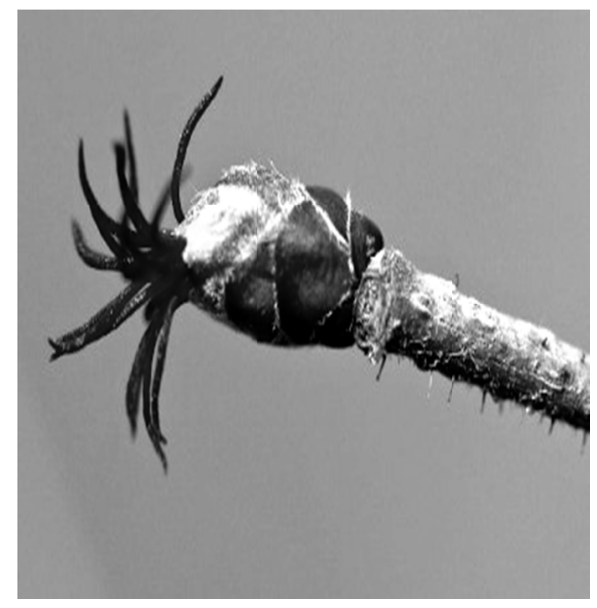

Figure 3. A single, terminal PI

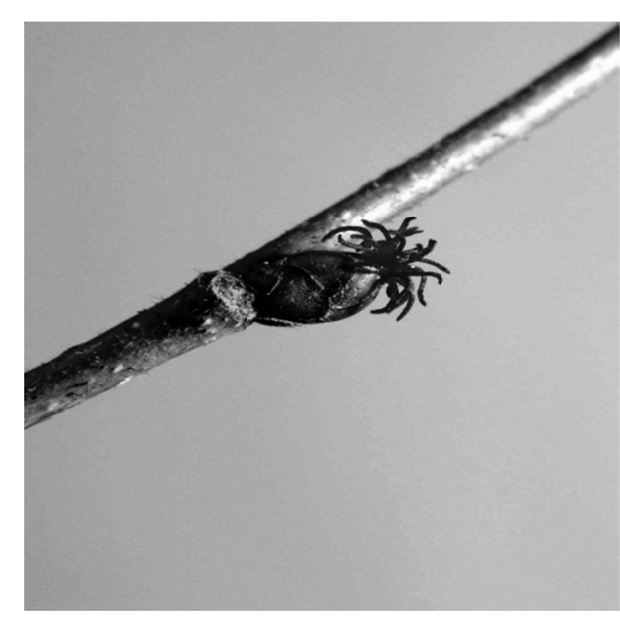

Figure 2. A single, lateral PI on the leaf scar axil of

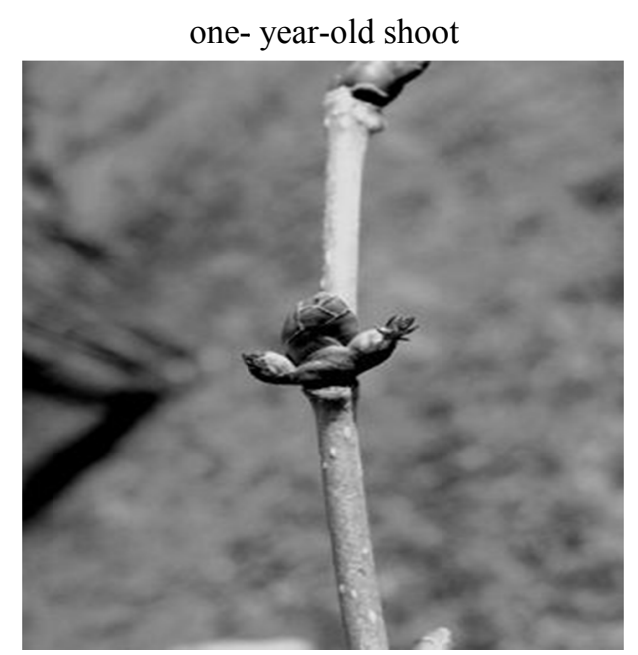

Figure 4. Two lateral PIs in one node adjacent to a vegetative bud 


\section{Materials and Methods}

This study was carried out during the winter of 2011, at the Astara Hazelnut Research Station in Astara, Guilan province, Iran (lat. $38^{\circ} 25^{\prime} \mathrm{N}$, long. $48^{\circ} 52^{\prime} \mathrm{E}$ ). The average annual precipitation is $1350 \mathrm{~mm}$, and the annual minimum and maximum temperatures are $-5^{\circ} \mathrm{C}$ and $36.5^{\circ} \mathrm{C}$, respectively. Six hazelnut cultivars were selected, including three local cultivars - "Pashmine", "Tabestane", and "Shastak"-and three imported cultivars "Barcelona" (USA), "Merveille" (syn. Merveille de Bollwiller) (France), and "Prostorika" (Russia). Each cultivar was represented by three trees. All trees were planted between 2000 and 2003. The trees were grown as multi-trunk shrubs on a spacing of $5 \times 5 \mathrm{~m}$ and were irrigated using a drip irrigation system. Trees were grown in full sun, with ample light exposure available to most branches including the inner parts of the canopy.

Four branches in different orientations (north, east, south, and west) were selected for each of the three trees per cultivar. Each branch was divided into equal thirds: basal, middle, and upper. The following characteristics were recorded for each branch section: number of flowering shoots (one-year-old shoots carrying PIs), number of flowering nodes (nodes carrying PIs), total number of PIs, percent of terminal (located at the end of the shoot) and lateral (located attached to the shoot) PIs, position of PIs on shoots [beside vegetative buds, on catkin peduncles, or single (no other buds nearby)], and number of pistillate flowers per inflorescence (from 40 inflorescences collected randomly from each tree). Information on the yield of these cultivars was assembled at the end of the season to investigate the relationship between PI characteristics and yield. Recorded data was analyzed using GENSTAT statistical software (Ver. 7, Lawes Agricultural Trust, Rothamsted Experimental Station) and the means were compared using LSD (0.05).

Table 1. Density and position of pistillate inflorescences (PIs) on branches of six hazelnut cultivars

\begin{tabular}{cccc}
\hline & $\begin{array}{c}\text { Pistillate flowering shoots } \\
\text { (no./1.0 m of branches) }\end{array}$ & $\begin{array}{c}\text { Flowering nodes } \\
\text { (no./1.0 m of branches) }\end{array}$ & $\begin{array}{c}\text { PIs } \\
\text { (no./1.0 m of branches) }\end{array}$ \\
\hline Cultivar & $P \leq 0.001$ & $P=0.125$ & $P=0.214$ \\
"Barcelona" & $9.03 \pm 1.53^{\mathrm{b}}$ & $16.39 \pm 3.19$ & $20.51 \pm 4.23$ \\
"Merveille" & $13.37 \pm 1.67^{\mathrm{a}}$ & $24.79 \pm 4.22$ \\
"Prostokarika" & $8.26 \pm 1.24^{\mathrm{b}}$ & $21.28 \pm 3.61$ & $19.29 \pm 3.92$ \\
"Pashmine" & $10.38 \pm 1.88^{\mathrm{b}}$ & $15.21 \pm 2.87$ & $22.09 \pm 4.8$ \\
"Shastak" & $10.38 \pm 2.41^{\mathrm{b}}$ & $21.45 \pm 4.60$ & $34.72 \pm 9.7$ \\
"Tabestane" & $13.73 \pm 1.63^{\mathrm{a}}$ & $29.12 \pm 8.40$ & $26.28 \pm 3.91$ \\
& & $22.71 \pm 3.14$ & $P=0.571$ \\
Origin of cultivar & $P=0.809$ & & $21.53 \pm 2.37$ \\
Local & $10.22 \pm 0.88$ & $P=0.366$ & $27.70 \pm 3.82$ \\
Imported & $11.50 \pm 1.16$ & $17.63 \pm 1.87$ & $P=0.826$ \\
& & $24.43 \pm 3.33$ & $23.73 \pm 3.8$ \\
Branch orientation & $P=0.957$ & & $22.55 \pm 4.3$ \\
North & $10.94 \pm 1.35$ & $20.61 \pm 3.13$ & $25.03 \pm 5.2$ \\
South & $10.62 \pm 1.45$ & $19.87 \pm 3.9$ & $27.12 \pm 4.6$ \\
West & $10.66 \pm 1.58$ & $21.02 \pm 4.6$ & $P \leq 0.001$ \\
East & $11.21 \pm 1.46$ & $22.63 \pm 3.7$ & $53.94 \pm 4.6^{\mathrm{a}}$ \\
Branch section & & & $13.67 \pm 1.92^{\mathrm{b}}$ \\
Upper & $P \leq 0.001$ & $46.09 \pm 4.0^{\mathrm{a}}$ & $6.21 \pm 1.62^{\mathrm{c}}$ \\
Middle & $20.94 \pm 1.1^{\mathrm{a}}$ & $11.54 \pm 1.39^{\mathrm{b}}$ & $5.44 \pm 1.32^{\mathrm{c}}$ \\
Basal & $7.90 \pm 0.83^{\mathrm{b}}$ & & \\
\hline
\end{tabular}

Mean \pm SEM. Means within a column followed by the same letter are not significantly different (LSD, 0.05).

Data represents average amounts from three trees of each cultivar.

In order to achieve a more normal distribution, data were transformed to square roots prior to analysis.

${ }^{\mathrm{y}}$ Pistillate flowering shoots: one-year-old shoots carrying pistillate inflorescences that arise from main branches which constitute growth two years old and older.

${ }^{\mathrm{z}}$ Flowering nodes: individual nodes where pistillate inflorescences are located. 


\section{Results and Discussion}

The results showed surprising similarities between the cultivars in terms of PIs position and density. While "Tabestane" and "Merveille" had a significantly higher number of pistillate flowering shoots than the group (13.73 and 13.37 per $1.0 \mathrm{~m}$ of branch, respectively; $P \leq 0.001$ ), all of the other cultivars were found to be similar (Table 1). Additionally, there were no significant differences between the cultivars in the density of pistillate flowering nodes or the total number of PIs per branch. Furthermore, no significant differences between the four geographic orientations in the density of flowering shoots, flowering nodes, and total number of PIs per branch were found in each cultivar $(P>0.05$ in all of them) (Table 1). Therefore, the amounts of flower induction and formation, and consequent fruit set, are probably similar in all orientations under the conditions present in this study.

For all cultivars, the three sections of the branches differed in their densities of flowering shoots, flowering nodes, and total number of PIs per branch $(P \leq 0.001)$. On average, there were 21.0 flowering shoots in every $1.0 \mathrm{~m}$ of the upper third, and only 7.9 in the middle and 3.7 in the basal sections. Similarly, the density of flowering nodes and total number of PIs were also much higher in the upper third (46.09 and 53.94 per m, respectively) compared to the middle (11.54 and 13.67) and basal (5.44 and 6.21) sections. This finding was expected as the increased amount of light received in the upper canopy has been reported to have a positive impact on flower formation (Germain, 1994). For this reason, it is suggested to avoid removing the upper sections of branches as much as possible during pruning to retain the highest areas of productivity.

Table 2. Percentage of pistillate inflorescences (PIs) found in different positions on flowering shoots of six hazelnut cultivars

\begin{tabular}{|c|c|c|c|c|}
\hline & $\begin{array}{c}\text { Terminal PIs } \\
(\%)^{\mathrm{y}} \\
\end{array}$ & $\begin{array}{c}\text { Lateral PIs } \\
(\%)^{\mathrm{y}}\end{array}$ & $\begin{array}{c}\text { PIs beside vegetative } \\
\text { bud }(\%)^{\mathrm{z}}\end{array}$ & $\begin{array}{c}\text { PIs on catkin } \\
\text { peduncles }(\%)^{\mathrm{z}}\end{array}$ \\
\hline Cultivar & $P \leq 0.001$ & $P \leq 0.001$ & $P=0.015$ & $P=0.015$ \\
\hline "Barcelona" & $40.61 \pm 6.40^{\mathrm{abc}}$ & $59.39 \pm 6.40^{\mathrm{abc}}$ & $69.61 \pm 6.53^{b}$ & $30.39 \pm 6.53^{a}$ \\
\hline "Merveille" & $61.41 \pm 5.03^{\mathrm{a}}$ & $38.59 \pm 5.03^{c}$ & $74.87 \pm 4.78^{b}$ & $25.13 \pm 4.78^{a}$ \\
\hline "Prostokarika" & $37.77 \pm 5.95^{b c}$ & $62.23 \pm 5.95^{\mathrm{ab}}$ & $70.65 \pm 6.85^{b}$ & $29.35 \pm 6.85^{\mathrm{a}}$ \\
\hline "Pashmine" & $24.35 \pm 7.29^{c}$ & $75.65 \pm 7.29^{\mathrm{a}}$ & $91.92 \pm 4.74^{\mathrm{a}}$ & $8.08 \pm 4.74^{b}$ \\
\hline "Shastak" & $32.82 \pm 6.50^{b c}$ & $67.18 \pm 6.50^{\mathrm{ab}}$ & $59.95 \pm 7.67^{b}$ & $40.05 \pm 7.67^{\mathrm{a}}$ \\
\hline "Tabestane" & $51.38 \pm 5.68^{\mathrm{ab}}$ & $48.62 \pm 5.68^{b c}$ & $77.01 \pm 4.45^{b}$ & $22.99 \pm 4.45^{\mathrm{a}}$ \\
\hline Origin of cultivar & $P=0.112$ & $P=0.112$ & $P=0.329$ & $P=0.329$ \\
\hline Local & $38.58 \pm 3.93$ & $61.42 \pm 3.93$ & $77.07 \pm 3.38$ & $22.93 \pm 3.38$ \\
\hline Imported & $47.57 \pm 3.49$ & $52.43 \pm 3.49$ & $71.95 \pm 3.43$ & $28.05 \pm 3.43$ \\
\hline Branch orientation & $P=0.425$ & $P=0.425$ & $P=0.607$ & $P=0.607$ \\
\hline North & $48.68 \pm 5.16$ & $51.32 \pm 5.16$ & $73.37 \pm 4.90$ & $26.63 \pm 4.90$ \\
\hline South & $38.18 \pm 5.25$ & $61.82 \pm 5.25$ & $79.90 \pm 3.99$ & $20.10 \pm 3.99$ \\
\hline West & $41.67 \pm 5.49$ & $58.33 \pm 5.49$ & $71.69 \pm 5.21$ & $28.31 \pm 5.21$ \\
\hline East & $44.09 \pm 5.26$ & $55.91 \pm 5.26$ & $72.75 \pm 5.17$ & $27.25 \pm 5.17$ \\
\hline Branch section & $P=0.004$ & $P=0.004$ & $P=0.104$ & $P=0.104$ \\
\hline Upper & $32.17 \pm 2.89^{b}$ & $67.83 \pm 2.89^{\mathrm{a}}$ & $73.07 \pm 2.92$ & $26.93 \pm 2.92$ \\
\hline Middle & $49.11 \pm 4.78^{\mathrm{ab}}$ & $50.89 \pm 4.78^{\mathrm{ab}}$ & $72.23 \pm 4.93$ & $27.77 \pm 4.93$ \\
\hline Basal & $60.51 \pm 7.02^{\mathrm{a}}$ & $39.49 \pm 7.02^{b}$ & $82.07 \pm 5.45$ & $17.93 \pm 5.45$ \\
\hline
\end{tabular}

Mean \pm SEM. Means within a column followed by the same letter are not significantly different (LSD, 0.05).

Data represents average amounts from three trees of each cultivar.

In order to achieve a more normal distribution, data were transformed to square roots prior to analysis.

${ }^{\mathrm{y}}$ Terminal PIs + Lateral PIs $=100 \%$.

${ }^{\mathrm{z}}$ PIs beside vegetative bud + PIs on catkin peduncles $=100 \%$.

The position of PIs located upon the flowering shoots are summarized in Table 2. There were highly significant differences between the cultivars in the percent of terminal and lateral PIs present $(P \leq 0.001)$. "Merville" had the highest number of inflorescences in terminal positions (61.41\%). In contrast, "Prostorika", "Pashmine", and "Shastak" all had a greater percent of lateral inflorescences compared to terminal inflorescences. In all cultivars, the number of PIs located beside vegetative buds was higher than the PIs located on catkin peduncles. "Pashmine" 
and "Tabestane" had a significantly higher number of PIs located beside vegetative buds compared to other cultivars $(P=0.015)$. The lowest percentage of PIs located on catkin peduncles $(8.08 \%)$ was observed in "Pashmine". Overall, there was no significant difference between Iranian and imported cultivars in the percent of PIs in different positions of the flowering shoots. Further, in all cultivars examined, most PIs were found in a lateral position and were located adjacent to vegetative buds.

Our results also showed that the orientation of the branch did not have a significant influence on the percent of terminal and lateral PIs present or the percent of PIs located beside vegetative buds and on catkin peduncles. Similarly, branch section was not found to have significant influence on the percent of PIs located beside vegetative buds and PIs on catkin peduncles; however, branch section was shown to have a significant influence on the percent of terminal and lateral PIs $(P=0.004)$. Generally, there were a higher percentage of terminal PIs at the basal section of the branches $(60.51 \%)$ compared to the other two sections. In contrast, there were more lateral PIs on upper section of the branches $(67.83 \%)$.

On flowering shoots of hazelnut, each node may contain one or more PIs. A summary of the percentage of nodes carrying one to five PIs for each cultivar is found in Table 3. In all cultivars, the majority of pistillate flowering nodes contained only one inflorescence $(78.94 \%-96.17 \%)$. It was followed by two and three inflorescences per node. Results showed that there were no significant differences between the cultivars in the percentage of nodes carrying one and three to four PIs, with significant influence found only on the percentage of nodes with two PIs ( $P$ $=0.049)$. "Barcelona" had the highest number of nodes with two PIs $(20.46 \%)$, while "Pashmine" and "Shastak" had the lowest number (2.98\% and 3.68\%, respectively). Furthermore, nodes with four inflorescences were rarely found in "Prostorika" $(2.88 \%)$ and "Shastak" $(0.20 \%)$, and "Shastak" was the only cultivar found containing nodes with five inflorescences $(0.44 \%)$. Further, no significant differences were observed among the four branch orientations and three branch sections in the percent of nodes with 1 to 5 PIs.

Table 3. Percentage of nodes with 1-5 pistillate inflorescences (PIs) on six hazelnut cultivars

\begin{tabular}{|c|c|c|c|c|c|}
\hline & $\begin{array}{c}\text { Nodes with } 1 \text { PI } \\
(\%)\end{array}$ & $\begin{array}{c}\text { Nodes with } 2 \text { PIs } \\
(\%)\end{array}$ & $\begin{array}{c}\text { Nodes with } 3 \\
\text { PIs (\%) }\end{array}$ & $\begin{array}{c}\text { Nodes with } 4 \text { PIs } \\
(\%)\end{array}$ & $\begin{array}{c}\text { Nodes with } 5 \\
\text { PIs (\%) }\end{array}$ \\
\hline Cultivar & $P=0.076$ & $P=0.049$ & $P=0.243$ & $P=0.417$ & $P=0.217$ \\
\hline "Barcelona" & $78.94 \pm 5.90$ & $20.46 \pm 6.40^{\mathrm{a}}$ & $2.78 \pm 1.59$ & 0 & 0 \\
\hline "Merville" & $88.65 \pm 3.40$ & $9.54 \pm 3.39^{\mathrm{ab}}$ & $1.81 \pm 1.40$ & 0 & 0 \\
\hline "Prostokarika" & $85.10 \pm 5.30$ & $8.56 \pm 3.40^{\mathrm{ab}}$ & $3.46 \pm 2.41$ & $2.88 \pm 2.88$ & 0 \\
\hline "Pashmine" & $96.17 \pm 2.32$ & $2.98 \pm 2.30^{b}$ & $0.76 \pm 0.76$ & 0 & 0 \\
\hline "Shastak" & $91.38 \pm 2.87$ & $3.68 \pm 2.25^{b}$ & $4.30 \pm 2.15$ & $0.20 \pm 0.20$ & $0.44 \pm 0.44$ \\
\hline "Tabestane" & $90.35 \pm 2.44$ & $8.54 \pm 2.25^{\mathrm{ab}}$ & $1.12 \pm 0.69$ & 0 & 0 \\
\hline Origin of cultivar & $P=0.187$ & $P=0.266$ & $P=0.868$ & $P=0.994$ & $P=0.885$ \\
\hline Local & $84.65 \pm 2.77$ & $12.40 \pm 2.56$ & $2.64 \pm 1.05$ & $0.95 \pm 0.95$ & 0 \\
\hline Imported & $92.52 \pm 1.50$ & $5.64 \pm 1.31$ & $1.83 \pm 0.68$ & $0.05 \pm 0.05$ & $0.11 \pm 0.11$ \\
\hline Branch Orientation & $P=0.339$ & $P=0.141$ & $P=0.084$ & $P=0.584$ & $P=0.388$ \\
\hline North & $85.89 \pm 3.47$ & $13.15 \pm 3.87$ & $2.12 \pm 1.35$ & $0.10 \pm 0.10$ & 0 \\
\hline South & $88.54 \pm 2.74$ & $7.75 \pm 2.49$ & $3.99 \pm 1.58$ & 0 & 0 \\
\hline West & $87.54 \pm 3.37$ & $11.41 \pm 3.17$ & $1.05 \pm 1.05$ & 0 & 0 \\
\hline East & $91.98 \pm 3.01$ & $3.96 \pm 1.64$ & $1.87 \pm 1.02$ & $1.97 \pm 1.97$ & 0.22 \\
\hline Branch section & $P=0.096$ & $P=0.199$ & $P=0.233$ & $P=0.322$ & $P=0.570$ \\
\hline Upper & $86.15 \pm 2.56$ & $10.12 \pm 2.07$ & $2.68 \pm 0.96$ & $1.10 \pm 1.10$ & 0.12 \\
\hline Middle & $90.10 \pm 2.32$ & $8.15 \pm 2.48$ & $2.69 \pm 1.27$ & 0 & 0 \\
\hline Basal & $91.29 \pm 4.09$ & $8.44 \pm 4.06$ & $0.27 \pm 0.27$ & 0 & 0 \\
\hline
\end{tabular}

Mean \pm SEM. Means within a column followed by the same letter are not significantly different (LSD, 0.05).

Data represents average amounts from three trees of each cultivar.

In order to achieve a more normal distribution, data were transformed to square roots prior to analysis. 
Significant differences were observed between the cultivars in terms of the number of pistillate flowers per inflorescence $(P<0.01)$. "Merveille" $(10.12)$ and "Barcelona" (7.62) had the highest and lowest average number of pistillate flowers per inflorescence, respectively (Table 4). Thompson et al. (1996) described the hazelnut PI as typically consisting of 4 to 14 small flowers, which are formed at the apex of a compound bud (Thompson et al., 1996). Interestingly, in this study, some inflorescences of "Merveille" had only two flowers and all of the cultivars except for "Barcelona" also had PIs containing 15-20 flowers. Table 4 also presents the average number of nuts per cluster and the recorded yield ( $\mathrm{kg}$ inshell nuts/tree) of all cultivars [data derived from Hosseinpour, 2011]. While "Merveille" had the highest number of pistillate flowers per inflorescence, it was found to produce on average few nuts (1-2) per cluster (Hosseinpour, 2011). Thus, more pistillate flowers per inflorescence will not necessarily lead to more nuts set in the cluster. Further, based on our data, no direct relationship between the pistillate flowers per inflorescence and the total yield collected could be resolved for each cultivar.

Table 4. Average number of pistillate flowers per inflorescence, nuts per cluster, and yield for six hazelnut cultivars

\begin{tabular}{lccc}
\hline Cultivar & $\begin{array}{c}\text { Average number of } \\
\text { pistillate flowers } \\
\text { per inflorescence }\end{array}$ & $\begin{array}{c}\text { Average number of nuts } \\
\text { per cluster }\end{array}$ & $\begin{array}{c}\text { Yield } \\
\text { (kg inshell nuts/ tree) })^{\mathrm{z}}\end{array}$ \\
\hline "Barcelona" & $7.62 \pm 0.18 \mathrm{c}$ & $2.42 \pm 0.12 \mathrm{c}$ & 3.4 \\
"Merville" & $10.12 \pm 0.27 \mathrm{a}$ & $1.30 \pm 0.06 \mathrm{~d}$ & 2.5 \\
"Prostorika" & $9.62 \pm 0.32 \mathrm{ab}$ & $3.15 \pm 0.2 \mathrm{ab}$ & 3.7 \\
"Pashmine" & $8.48 \pm 0.19 \mathrm{bc}$ & $1.40 \pm 0.09 \mathrm{~d}$ & 3.0 \\
"Shastak" & $9.07 \pm 0.21 \mathrm{ab}$ & $2.75 \pm 0.17 \mathrm{bc}$ & 1.5 \\
"Tabestane" & $8.78 \pm 0.22 \mathrm{abc}$ & $2.37 \pm 0.15 \mathrm{c}$ & 2.3 \\
\hline
\end{tabular}

${ }^{y}$ Mean \pm SEM. Means within a column followed by the same letter are not significantly different (LSD, 0.05). 40 inflorescences per cultivar were analyzed.

${ }^{\mathrm{z}}$ Data on nuts per cluster and yield are from Hosseinpour 2011.

\section{Conclusion}

With the exception of "Tabestane" and "Merveille", results showed a strong similarity between cultivars in the density of flowering shoots per branch, with all cultivars similar in terms of the number of flowering nodes and PIs within the branches. Further, across the cultivars, geographic orientation did not have a significant influence on the density of flowering shoots, flowering nodes, and PIs. However, significant variability was observed between cultivars in the percent of terminally and laterally located PIs and the average number of pistillate flowers found per inflorescence. Interestingly, an increased number of pistillate flowers per inflorescence did not necessarily result in more nut set per cluster. In general, the density of PIs was significantly higher in the upper section of the branches when compared to the middle and basal portions. Most PIs found in this section were lateral, while the majority of the PIs located in the basal section were terminal. Across all cultivars, most of the PIs found in nodes were singles, with only a few of the nodes carrying two or more inflorescences. Overall, these preliminary results suggest that the Iranian and imported cultivars do not differ much in the characteristics of their PIs. This finding indicates that additional factors such as successful pollination must play a significant role in nuts produced per cluster, as well as total yield, on which notable differences are present between the cultivars. Further investigations are needed in additional years to draw strong conclusions on the relationship between hazelnut pistillate inflorescences and their impact on total yield. It is hoped that the results presented here provide a foundation from which additional, longer-term studies can be completed on the relationships between PI characteristics and yield in hazelnut.

\section{Acknowledgement}

The authors would like to thank Saeed Hosseinpour for assistance in collecting data and John Capik for his help reviewing the manuscript.

\section{References}

Alburquerque, N., Burgos, L., \& Egea, J. (2004). Influence of flower bud density, flower bud drop and fruit set on apricot productivity. Sci. Hortic., 102, 397-406. http://dx.doi.org/10.1016/j.scienta.2004.05.003

Germain, E. (1994). The reproduction of hazelnut (Corylus avellana L.): A review. Acta Hortic., 351, 195-210. 
Hanke, M. V., Flachowsky, H., Peil, A., \& Hättasch, C. (2007). No flower no fruit - genetic potentials to trigger flowering in fruit trees. Genes, Genomes and Genomics, 1, 1-20.

Hosseinpour, A. (2011). Investigation of pollen incompatibility and some nut and kernel characteristics in some hazelnut cultivars (pp. 1-130). MS Thesis. Gorgan University of Agricultural Sciences and Natural Resources, Gorgan, Iran.

Kodad, O., \& Company, R. S. I. (2006). Influence of genotype, year and type of fruiting branches on the productive behaviour of almond. Sci. Hortic., 109, 297-302. http://dx.doi.org/10.1016/j.scienta.2006.05.002

Mehlenbacher, S. A. (1997). Revised dominance hierarchy for S-alleles in Corylus avellana L. Theor. Appl. Genet., 94, 360-366. http://dx.doi.org/10.1007/s001220050424

Okie, W. R., \& Werner, D. J. (1996). Genetic influence on flower bud density in peach and nectarine exceeds that of environment. Hortscience, 31, 1010-1012.

Seifi, E., Guerin, J., Kaiser, B., \& Sedgley, M. (2011). Sexual compatibility and floral biology of some olive cultivars. N. Z. J. Crop Hortic. Sci., 39, 141-151. http://dx.doi.org/10.1080/01140671.2011.560165

Socias i Company, R., Alonso, J. M., \& Aparisi, J. G. (2004). Fruit set and productivity in almond as related to self-compatibility, flower morphology and bud density. J. Hortic. Sci. Biotech., 79, 754-758.

Socias i Company, R., Felipe, A. J., Aparisi, J. G., García, J. E., \& Dicenta, F. (1998). The ideotype concept in almond. Acta Hortic., 470, 51-56.

Thompson, M. M., Lagerstedt, H. B., \& Mehlenbacher, S. A. (1996). Hazelnuts. In J. Janick, J. N. Moore (Eds.), Fruit Breeding. New York: John Wiley \& Sons.

Werner, D. J., Mowrey, B. D., \& Chaparro, J. X. (1988). Variability in flower bud number among peach and nectarine clones. Hortscience, 23, 578-580. 